OPEN ACCESS

Edited by:

Wee-Jun Ong,

Xiamen University, Malaysia

Reviewed by:

Taohai Li,

Xiangtan University, China

Weizhen Liu,

South China University of

Technology, China

*Correspondence:

Zhi Chen

chenzhi0529@163.com

Specialty section:

This article was submitted to Catalysis and Photocatalysis,

a section of the journal

Frontiers in Chemistry

Received: 28 December 2019

Accepted: 14 February 2020

Published: 17 March 2020

Citation:

Xing R-Z, Li J-X, Yang $X-G$, Chen $Z-W$, Huang $R$, Chen Z-X, Zhou S-G and

Chen Z (2020) Preparation of

High-Performance CdS@C Catalyst Using Cd-Enriched Biochar Recycled

From Plating Wastewater.

Front. Chem. 8:140.

doi: 10.3389/fchem.2020.00140

\section{Preparation of High-Performance CdS@C Catalyst Using Cd-Enriched Biochar Recycled From Plating Wastewater}

\author{
Rui-Zhi Xing, Jia-Xin Li, Xing-Gui Yang, Ze-Wei Chen, Rong Huang, Zhi-Xuan Chen, \\ Shun-Gui Zhou and Zhi Chen*
}

Fujian Provincial Key Laboratory of Soil Environmental Health and Regulation, College of Resources and Environment, Fujian Agriculture and Forestry University, Fuzhou, China

Biochar is widely used for the adsorptive removal of $\mathrm{Cd}$ from water and soil, but the $\mathrm{Cd}$-enriched biochar produced carries a risk of secondary pollution. In this work, biochar derived from rice straw was used to adsorb $\mathrm{Cd}$ from plating wastewater. The $\mathrm{Cd}$-enriched biochar showed a saturated adsorption capacity of about $63.5 \mathrm{mg} / \mathrm{g}$ and could be recycled and used in a mesoporous carbon-supported CdS (CdS@C) photocatalyst after pyrolysis carbonization and a hydrothermal reaction. The results demonstrated that the as-prepared CdS@C photocatalyst contained mixed cubic and hexagonal CdS phases, with a considerably lower band gap (2.1 eV) than pure CdS $(2.6 \mathrm{eV})$. CdS@C exhibited an enhanced photocatalytic performance for the degradation of organic dyes under visible light irradiation compared with pure CdS due to its excellent light-harvesting capacity and efficient electron-hole separation. Moreover, the continuous formation of active species $\left(\mathrm{h}^{+}, \cdot \mathrm{OH}\right.$, and $\left.\mathrm{O}_{2} \cdot{ }^{-}\right)$was responsible for the photodegradation of organic dyes using CdS@C. This work provides new insights for the safe disposal of Cd-enriched wastewater and for improving the economic viability of $\mathrm{Cd}$-contaminated resources by recovering a value-added photocatalyst.

Keywords: biochar, photocatalyst, adsorption, cadmium sulfide, hazardous waste

\section{INTRODUCTION}

Cadmium $(\mathrm{Cd})$ is extremely toxic to plants and poses a serious threat to humans and animals when it enters the food chain (Clemens et al., 2013; Zhao et al., 2015; Gong et al., 2019; Hussain et al., 2019). It is introduced into the environment through the discharge of Cd-containing wastewater from industrial processes involved in electroplating, photovoltaics, and metal smelting (Hayat et al., 2019; Nain and Kumar, 2019; Król et al., 2020). Biochar is an ideal adsorbent for the removal of heavy metals from aqueous environments due to its low cost, widespread availability, ecofriendliness, and high adsorption capacity (Inyang et al., 2012; Harsono et al., 2013; Xu et al., 2013; Chen et al., 2018; Ahmed et al., 2019). In fact, biochar derived from different biomass materials has been investigated to develop alternative adsorption techniques for the removal of $\mathrm{Cd}$ from contaminated environments (Chen et al., 2015, 2018, 2019a; Wu et al., 2019). The majority of studies have focused on the modification of biochar to enhance its adsorption capacity (Chen et al., 2015, 2018, 2019b; Wu et al., 2019). However, fewer studies have attempted to identify an appropriate strategy for the disposal and upcycling of Cd-enriched biochar after adsorption, which poses a secondary pollution risk. The Cd accumulated on biochar can be released back into 
surrounding environments by leaching or other natural processes when it is disposed of in a landfill (He et al., 2019; Wang et al., 2019; Zhang et al., 2020). Thus, there is a need to identify a safe and economically viable disposal method for Cd-enriched biochar.

A promising disposal method for metal-enriched hazardous waste is upcycling in the form of high value-added products (Harumain et al., 2017; Cui et al., 2018; Ye et al., 2019). In principle, noble metals (e.g., $\mathrm{Ni}, \mathrm{Au}, \mathrm{Cu}$, and $\mathrm{Pt}$ ) can be directly recovered by incineration/pyrolysis or leaching (Keller et al., 2005; Zhang et al., 2014; Guilpain et al., 2018). However, Cd is not a valuable heavy metal, and it is not economically viable to extract it directly from Cd-accumulated hazardous waste (Sadegh et al., 2007; Chen et al., 2019c). Interestingly, some metal-enriched hazardous wastes have shown great potential for upcycling as catalysts (Parker et al., 2014; Harumain et al., 2017; Chen et al., 2019c,d). For example, palladium in metal-enriched hazardous wastes can be recovered in the form of high-value carbonsupported catalysts (Parker et al., 2014; Harumain et al., 2017). In addition, our previous works have suggested that Cd-enriched biomass can be transformed into a CdS@C composite with high photocatalytic performance (Chen et al., 2019c,d). The carbon carrier prevented the aggregation and photocorrosion of catalyst particles and facilitated the transport and contact of substrates between the support and the active sites (Gao et al., 2011; Han et al., 2011; Huang et al., 2018; Chen et al., 2019c). In light of these advantages, biochar-supported CdS composites may greatly enhance the photocatalytic activity and stability of the catalysts (Ma et al., 2017; Huang et al., 2018, 2019; Bantawal et al., 2019; Cao et al., 2019; Hu et al., 2019).

Biochar has been widely used for $\mathrm{Cd}$ adsorption or immobilization in environmental remediation because it is capable of adsorbing high levels of Cd ( $>1 \%$, dry weight) (Chen et al., 2015, 2018, 2019b; Wu et al., 2019). However, no research has been conducted to identify a feasible way to recycle Cdenriched biochar into a catalyst. Such a method could achieve the dual effect of high-value utilization and secondary pollution risk management. In this work, we developed a facile and lowcost method for the preparation of a CdS@C photocatalyst by recycling Cd-enriched biochar after treatment of Cdcontaining plating wastewater. The photocatalytic performance and photodegradation mechanism of CdS@C for the degradation of organic pollutants were investigated.

\section{EXPERIMENTAL}

\section{Materials}

Sodium sulfide $\left(\mathrm{Na}_{2} \mathrm{~S} \cdot 2.5 \mathrm{H}_{2} \mathrm{O}, \geq 98 \%\right)$, rhodamine B ( $\mathrm{RhB}$, 95\%), methylene blue (MB, 95\%), acid red 11 (AR11, 96\%), and 5,5'-dimethyl-1-pyrroline-N-oxide (DMPO, 97\%) were commercially purchased. Deionized water was used to prepare reaction and stock solutions. The rice straw biomass was picked from the College of Life Sciences, Fujian Agriculture and Forestry University (Figure S1). The cadmium plating wastewater was taken from an electroplating factory in Quanzhou, Fujian Province, China. The physiochemical parameters of the cadmium plating wastewater are listed in Table S1.

\section{Fabrication of CdS@C Composite Photocatalyst}

The rice straw biomass was washed with deionized water and dried for $12 \mathrm{~h}$ in an oven at $105^{\circ} \mathrm{C}$. The rice straw was then ground into a powder of about 100 mesh and carbonized in a tube furnace at $700^{\circ} \mathrm{C}$ under a nitrogen atmosphere for $3 \mathrm{~h}$ to obtain biochar capable of adsorbing Cd. About $0.5 \mathrm{~g}$ biochar was added into $150 \mathrm{~mL} \mathrm{Cd}$-containing plating wastewater and stirred with a magnetic stirrer for $40 \mathrm{~min}$. After adsorption, Cdenriched biochar (denoted as Cd-Biochar) was obtained through centrifugation, followed by washing with deionized water and drying at $60^{\circ} \mathrm{C}$ for $24 \mathrm{~h}$.

Under an $\mathrm{N}_{2} / \mathrm{O}_{2}(6 / 1, \mathrm{v} / \mathrm{v})$ mixed atmosphere, Cd-Biochar was oxidized at $650^{\circ} \mathrm{C}$ for $0.5 \mathrm{~h}$, which increased the cadmium content in the biochar from 2.5 to $5 \%$. This was dispersed into a $5 \mathrm{mM} \mathrm{Na}_{2} \mathrm{~S}$ solution in a Teflon-lined stainless steel pot, heated in a muffle furnace at $180^{\circ} \mathrm{C}$ for $72 \mathrm{~h}$, and then cooled to ambient temperature.The CdS@C composite photocatalyst was obtained after washing with deionized water and filtering (Chen et al., 2019c).

\section{Characterization}

Scanning electron microscopy (SEM) images were acquired using a JSM6700-F (JEOL, Japan) operating at $10 \mathrm{kV}$ to compare the surface morphology of biochar before and after synthesis. Inductively coupled plasma mass spectrometry (ICP-MS) and elemental analysis (EA) were used to determine the contents of C, $\mathrm{H}, \mathrm{S}$, and $\mathrm{Cd}$ in the material. Transmission electron microscopy (TEM) and high-resolution TEM (HRTEM) images were used to determine the crystal morphology and phase of the materials using a JEM-2010 at $200 \mathrm{kV}$. X-ray powder diffraction (XRD) patterns were used to determine the composition and molecular structure of the materials; these patterns were obtained using the Ultima IV (Rigaku, Japan), operating at a $40-\mathrm{kV}$ tube voltage and a $40-\mathrm{mA}$ tube current. X-ray photoelectron spectroscopy (XPS) was carried out to analyze the valence states of elements using an ESCALAB 250 (Thermo Fisher, America) with an Al/Mg double anode target as the radiation source $(15 \mathrm{kV}, 10 \mathrm{~mA})$. The C 1s peak at $284.7 \mathrm{eV}$ was used to calibrate the energy scale of the XPS spectra. The diffuse reflectance spectra (DRS) were recorded from 200 to $800 \mathrm{~nm}$ on an UV2550 UV-Vis spectromater (Shimadzu, Japan) using a $\mathrm{BaSO}_{4}$ background. The band gap energy $\left(E_{g}\right)$ of the photocatalyst was calculated by the Kubelka-Munk (K-M) formula:

$$
(A h v / K)^{2}=h_{v}-E_{g} .
$$

where $A$ is the absorbance, $h_{\mathrm{v}}$ is $1,240 /$ wavelength, and $K$ is a constant. The electron spin resonance (ESR) spectra were obtained of active substances produced by visible light irradiation using a Bruker A300 spectrometer (Bruker, Germany).

\section{Photocatalytic Degradation of Organic Dyes}

The role of $\mathrm{RhB}$ in photocatalytic degradation was studied. In a general catalysis procedure, photocatalyst $(20.0 \mathrm{mg})$ was 
dispersed in $100 \mathrm{~mL}$ of a photocatalytic reactor with a $50 \mathrm{~mL}$ $\mathrm{RhB}$ solution (with a final $\mathrm{RhB}$ concentration of $40.0 \mathrm{mg} / \mathrm{L}$ ). The samples were magnetically stirred at $800 \mathrm{rpm}$ for $30 \mathrm{~min}$ in the dark. A xenon lamp (CEL-HXF300, Beijing) equipped with cut-off filters at 420 and $780 \mathrm{~nm}$ was used as the light source. After visible light irradiation for a certain period of time, the photocatalytic absorbance experiments were monitored by a 554-nm ultraviolet-visible spectrophotometer. The efficiency of photocatalysis was calculated by the following formula:

$$
R=C / C_{0} \times 100 \%
$$

where $R$ is the degradation rate, $C_{0}$ is the characteristic absorbance of $\mathrm{RhB}$ before photocatalysis, and $C$ is the characteristic absorbance of $\mathrm{RhB}$ after photocatalysis (Huang et al., 2017).

\section{Photocatalytic Mechanism Analysis}

The current vs. time (I-t) curves were obtained using a Shanghai Chenhua CHI600E electrochemical workstation. First, $5 \mathrm{mg}$ of a sample was ultrasonically dispersed in a $5 \%$ naphthene solution. About $5 \mu \mathrm{l}$ of the suspension was then uniformly smeared on an ITO glass substrate $(1 \mathrm{~cm} \times 1 \mathrm{~cm})$ and allowed to dry at room temperature. The coating process was repeated 10 times to form a thin film on the ITO glass substrate. The change in the instantaneous current with time was used to evaluate whether the photocatalyst had a photoelectric effect. An electron spin resonance (ESR) spectrometer (Bruker A300) was used to detect the presence of superoxide radical $\left(\mathrm{O}_{2}{ }^{-}\right)$during photocatalytic reactions using the capture agent DMPO. Hydroxyl radicals $(\cdot \mathrm{OH})$ generated during the photocatalytic reaction could react with terephthalic acid (TA) to produce highly fluorescent 2hydroxyterephthalic acid (TAOH), and the fluorescence was detected by fluorescence spectroscopy.

\section{RESULTS AND DISCUSSION \\ Preparation and Characterization of CdS@C Photocatalyst}

Rice straw biochar was used to recycle $\mathrm{Cd}$ from plating wastewater and then converted into a CdS@C composite using the route shown in Scheme 1. The Cd equilibrium adsorption of the biochar was achieved in 30-40 min and reached about $63.5 \mathrm{mg} / \mathrm{g}$ (Figure S2). The Cd-Biochar was further converted into a CdS@C composite in a stepwise process, as reported in our previous works (Chen et al., 2019c,d). The secondary pyrolysis of Cd-Biochar was conducted under an $\mathrm{N}_{2} / \mathrm{O}_{2}(6 / 1, \mathrm{v} / \mathrm{v})$ atmosphere at $650^{\circ} \mathrm{C}$ before the sulfuration (Chen et al., 2019c). The elemental analysis indicated that the $\mathrm{S}$ and $\mathrm{Cd}$ contents were ca. $4.4 \%$ and ca. $16.1 \%$, respectively, in the synthetic material after Cd concentration and sulfuration (Table $\mathbf{1}$ ).

The microscopic surface texture of Cd-Biochar and asprepared CdS@C composite were investigated by SEM. The CdBiochar exhibited obvious porous tubular structures with a rough and hierarchical surface (Figure 1a). After Cd concentration and sulfuration, many uniformly distributed particles were observed on the surface of the as-prepared CdS@C composite (Figure 1b). The EDX elemental analysis suggested that the particles on the

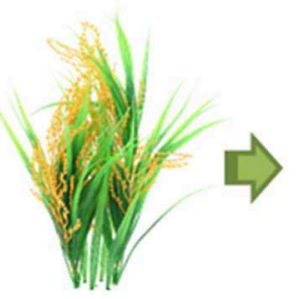

Redundant biomass

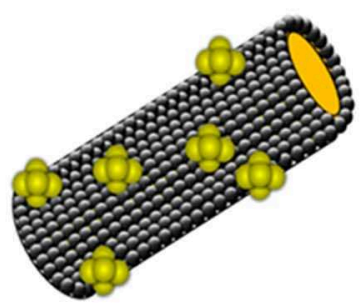

CdS@C

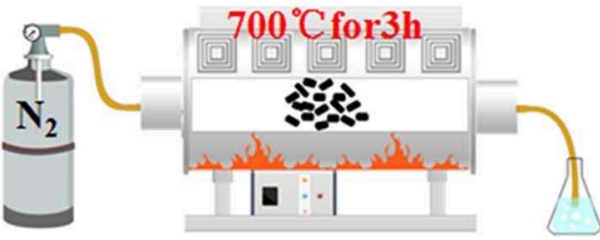

Step I : Carbonization
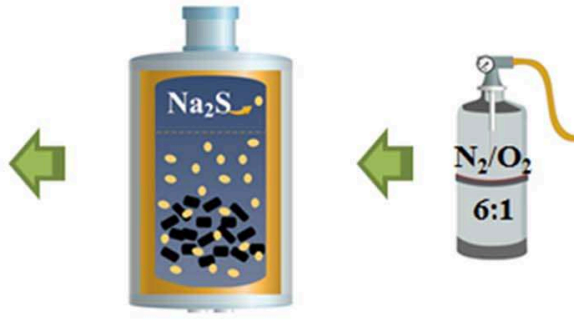

Step II : Cd-adsorption from

Step IV : Sulfuration plating wastewater
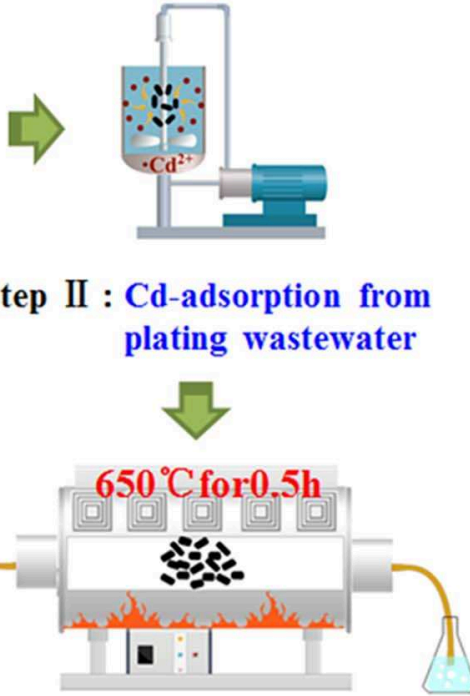

Step III : Cd Concentration

SCHEME 1 | Diagram of the route for CdS@C synthesis route. 
TABLE 1 | Elemental analysis of the Cd-Biochar and CdS@C.

\begin{tabular}{lcccc}
\hline \multirow{2}{*}{ Samples } & \multicolumn{4}{c}{ Element } \\
\cline { 2 - 5 } & $\mathbf{C ~ ( \% )}$ & $\mathbf{H}(\%)$ & $\mathbf{S}(\%)$ & $\mathbf{C d}(\%)$ \\
\hline Cd-Biochar & 55.7 & 1.1 & 0.4 & 6.3 \\
CdS@C & 21.4 & 1.0 & 4.4 & 16.1 \\
\hline
\end{tabular}

surface of the composite were mainly composed of S and Cd (Figure S3).

The chemical composition, the valence state of the elements, and surface functionality groups of CdS@C were further characterized by XPS. As shown in Figure 2, the wide-scan XPS spectra of the composite contain Cd 3d, S 2p, O 1s, and $\mathrm{C}$ 1s signals (Figure 2A). The deconvoluted high-resolution spectrum demonstrated that the $\mathrm{Cd} 3 \mathrm{~d}$ spectrum contained peaks at $405.6 \mathrm{eV}\left(\mathrm{Cd} 3 \mathrm{~d}_{5 / 2}\right)$ and $412.3 \mathrm{eV}\left(\mathrm{Cd} 3 \mathrm{~d}_{3 / 2}\right)$, which was consistent with the characteristic peaks of $\mathrm{Cd}^{2+}$ in $\mathrm{CdS}$ (Figure 2B) (Huang et al., 2018; Chen et al., 2019c). The deconvoluted $S 2 p_{3 / 2}$ and $S 2 p_{1 / 2}$ peaks at 161.8 and $163.7 \mathrm{eV}$ indicated the presence of $S^{2-}$ in the composites (Figure 2C) (Ye et al., 2012; Huang et al., 2018). The Cd 3d and S 2p XPS spectra confirmed the presence of CdS in the as-prepared composite. The C1s peak-fitting showed four peaks at 284.7, 286.3, 287.8, and $289.5 \mathrm{eV}$, respectively (Figure 2D). The peak at $284.7 \mathrm{eV}$ was assigned to the $\mathrm{sp}^{2}$ carbon species, while the peaks at 286.3, 287.8 , and $289.5 \mathrm{eV}$ were identified as oxygenated carbon species (i.e., $\mathrm{C}-\mathrm{O}, \mathrm{C}=\mathrm{O}$, and COOR) (Okpalugo et al., 2005; Ye et al., 2012). The binding energies in the high-resolution C1s XPS spectrum suggested that the carbon support was functionalized with oxygen-containing groups. Additionally, the wide-scan XPS spectrum also confirmed the presence of other mineral elements, such as Mn and Ca (Figure 2D).

XRD and TEM were used to confirm the presence of CdS in the composite. As shown in Figure 3a, the Cd-Biochar and the composite showed different characteristic peaks in their XRD patterns. The diffraction peaks of the composite exhibited a mixture of cubic (PDF 42-1411) and hexagonal phase (PDF 010783) CdS. In addition, the HRTEM images of the CdS particles on the composite showed two different crystal lattice spacings of 0.298 and $0.318 \mathrm{~nm}$, which were assigned to the characteristic (111) and (101) crystal planes of cubic and hexagonal CdS, respectively (Figure $\mathbf{3 b}$ ). Thus, XPS, XRD, and TEM results verified that the $\mathrm{Cd}$-Biochar was recycled in the form of CdS@C composite. It is worth noting that the CdS@C composite was prepared by recycling of $\mathrm{Cd}$ from plating wastewater. Additionally, Cd-enriched hyperaccumulator biomass could also be used to synthesize a CdS@C photocatalyst, as reported in our previous works (Chen et al., 2019c,d). This study suggests that CdS@C can be synthesized using a facile and low-cost method by upcycling different types of Cd-enriched biomasses.

The visible-light absorption properties of CdS@C composite were investigated by UV-Vis diffuse reflectance spectroscopy (DRS) to evaluate its photocatalytic activity. As shown in Figure 4A, compared with pure $\mathrm{CdS}$, the light absorption of CdS@C from 350 to $750 \mathrm{~nm}$ was increased, suggesting a more efficient light-harvesting of CdS@C in photocatalysis under visible irradiation (Apte et al., 2012). According to the KubelkaMunk formula, the bandgap energy of the CdS@C was $2.1 \mathrm{eV}$, which was lower than that of pure CdS (ca. 2.6 eV) (Figure 4B), suggesting a better photocatalytic performance under visible light irradiation. The bandgap energy of CdS@C was similar to a previously reported CdS composite catalyst prepared by loading hydrothermally prepared CdS precursors on biochar (Zhu et al., 2017).

\section{Photocatalytic Properties of CdS@C in Organic Dyes Degradation}

Previous works have demonstrated that mixed-phase CdS composites supported on porous materials have strong photocatalytic activities (Dai et al., 2014; Li et al., 2016). The photocatalytic activity of CdS@C was evaluated by the photodegradation of organic dyes under visible light irradiation. As shown in Figure 5, the photocatalytic efficiency of CdS@C was generally significantly higher than that of pure CdS. The RhB photodegradation of CdS@C was about 98.6\% after irradiation for $120 \mathrm{~min}$, while the $\mathrm{RhB}$ photodegradation efficiency using pure CdS was considerably lower at about $39.1 \%$ under the same conditions (Figure 5A). The photodegradation of $\mathrm{MB}$ and AR11 confirmed that the photocatalytic activity of CdS@C was enhanced compared with pure CdS (Figure 5B). Additionally, the photodegradation efficiency of $\mathrm{RhB}$ and $\mathrm{MB}$ was considerably higher than that of AR11 under photocatalysis using CdS@C. This may be due to the fact that $\mathrm{RhB}$ and $\mathrm{MB}$ are cationic dyes, whereas AR11 is anionic. Electrostatic adsorption between cationic dyes (i.e., $\mathrm{RhB}$ and $\mathrm{MB}$ ) and the negatively charged CdS@C could promote favorable transport and contact between organic dyes during photocatalysis (Lv et al., 2005; Mahmoodi et al., 2011; Mittal and Khanuja, 2019). It was believed that the enhanced photocatalytic activity of CdS@C was attributable to improved substrate accessibility, light-harvesting efficiency, and electron-hole separation due to the porous carbonaceous carrier (Huang et al., 2018).

For practical applications, an ideal photocatalyst will have high durability in addition to high photoactivity. The reusability and stability of CdS@C were further tested by recycling it after RhB degradation. Figure $\mathbf{6 A}$ shows that the photocatalytic activity remained above $70 \%$ of its initial value after four consecutive degradation cycles. The decreased photocatalytic activity may have been due to the deactivation and agglomeration of CdS, as well as the loss of CdS@C photocatalyst during the water washing-drying process. No significant changes were detected in the XRD patterns of CdS@C before and after 4 cycles of $\mathrm{RhB}$ photodegradation (Figure 6B). This indicates that the structure and composition of CdS@C were stable during photocatalysis, suggesting that the composite had good reusability and stability.

\section{Photocatalytic Degradation Mechanism of Organic Dyes Using CdS@C}

It was speculated that the photogenerated electron-hole pairs of CdS could be efficiently separated by the biochar carrier, leading to enhanced photocatalytic performance of the CdS@C 


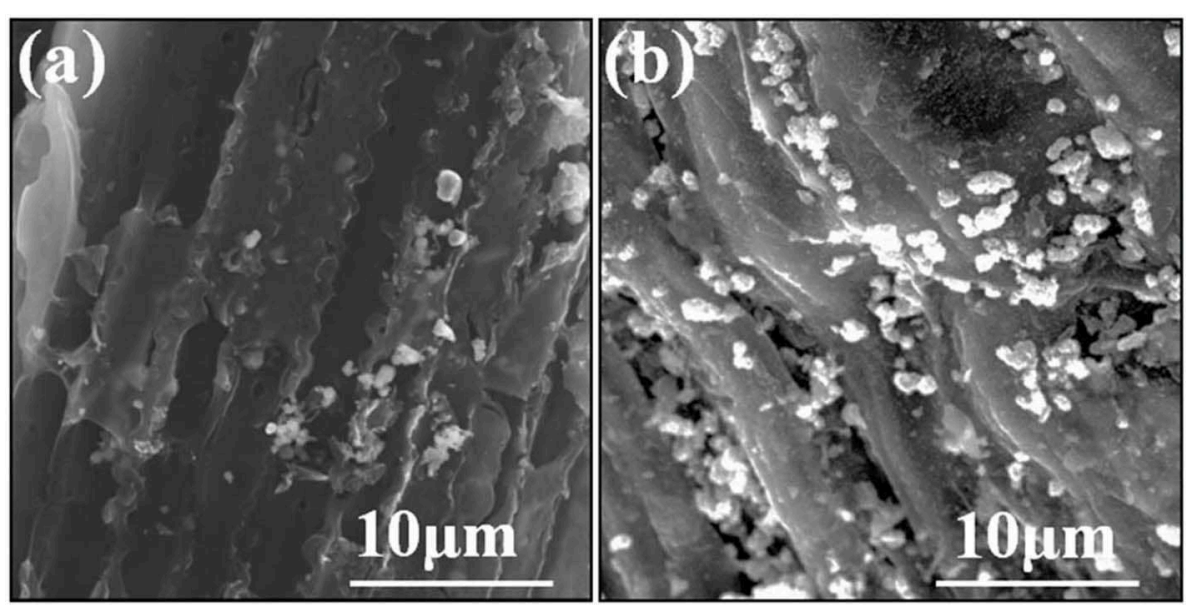

FIGURE 1 | SEM images of Cd-Biochar (a) and CdS@C (b)

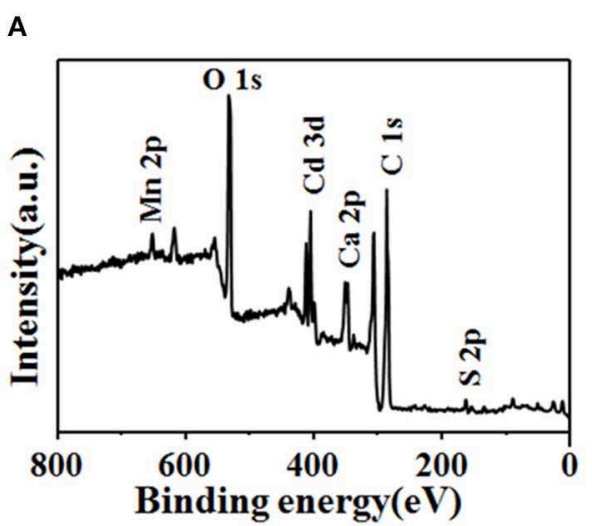

C

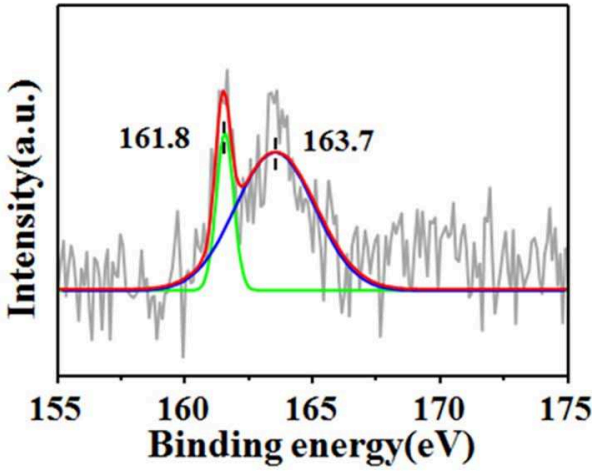

B

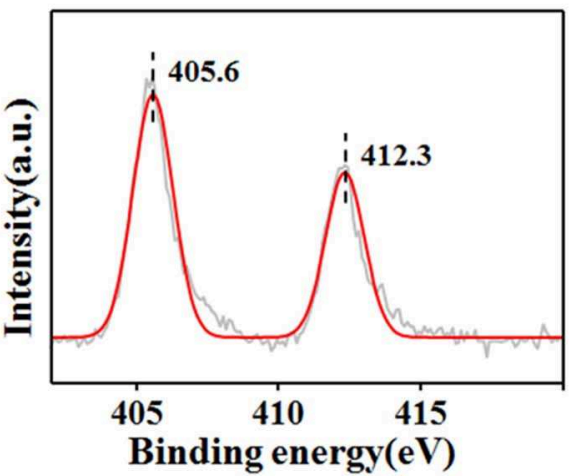

D

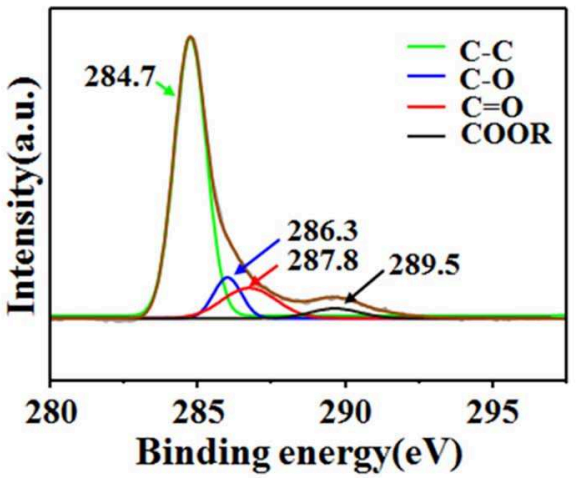

FIGURE 2 | XPS spectral of CdS@C (A) and high-resolution XPS spectra of Cd 3d (B), S 2p (C), and C 1s (D).

composite (Lei et al., 2017). The transient photocurrent responses were measured to assess the generation and transport of photogenerated electrons during photocatalysis using CdS@C under intermittent visible-light illumination. As shown in Figure 7A, a photocurrent was rapidly generated and remained stable for $30 \mathrm{~s}$ during illumination, and immediately decreased to zero when illumination was stopped. Obviously, the photocurrent of the CdS@C was significantly higher than that of pure CdS under the same irradiation conditions, indicating an enhanced separation and transport of electron-hole pairs ( $\mathrm{Li}$ et al., 2018). As a consequence, the charge recombination was reduced, and more reactive species such as $h^{+}$and $\mathrm{O}_{2}{ }^{-}$, were produced. Additionally, $h^{+}$and $\mathrm{O}_{2} \cdot{ }^{-}$could produce $\cdot \mathrm{OH}$. To verify the presence of $\bullet \mathrm{OH}$ and $\mathrm{O}_{2}{ }^{-}-$during photocatalysis using 

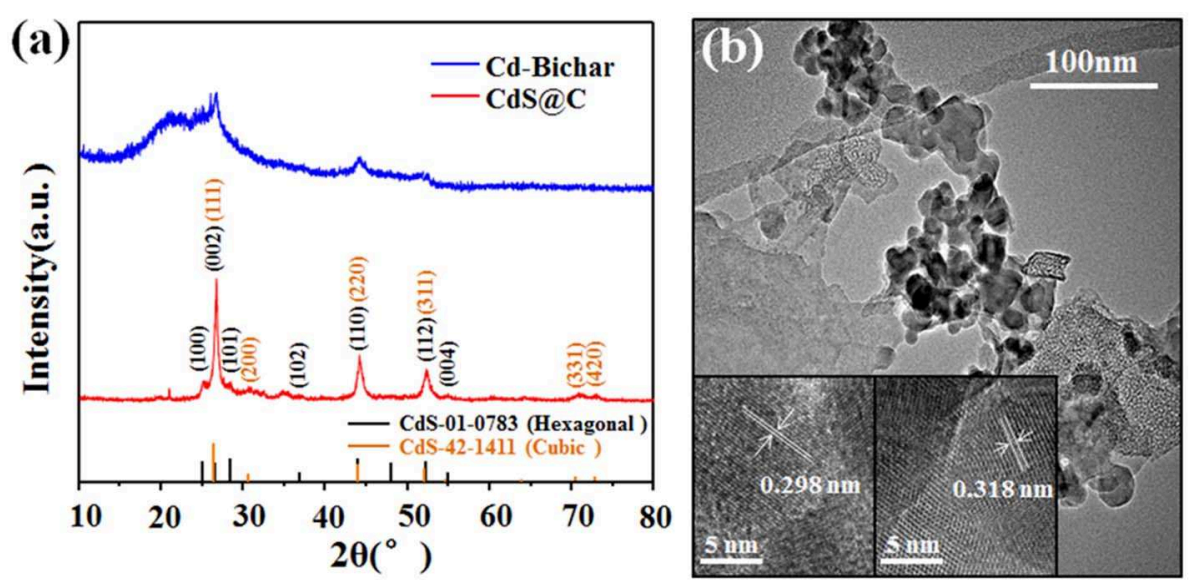

FIGURE 3 | XRD patterns of the Cd-Biochar and CdS@C composite materials (a); TEM image of CdS@C (b) (insets are HRTEM images).
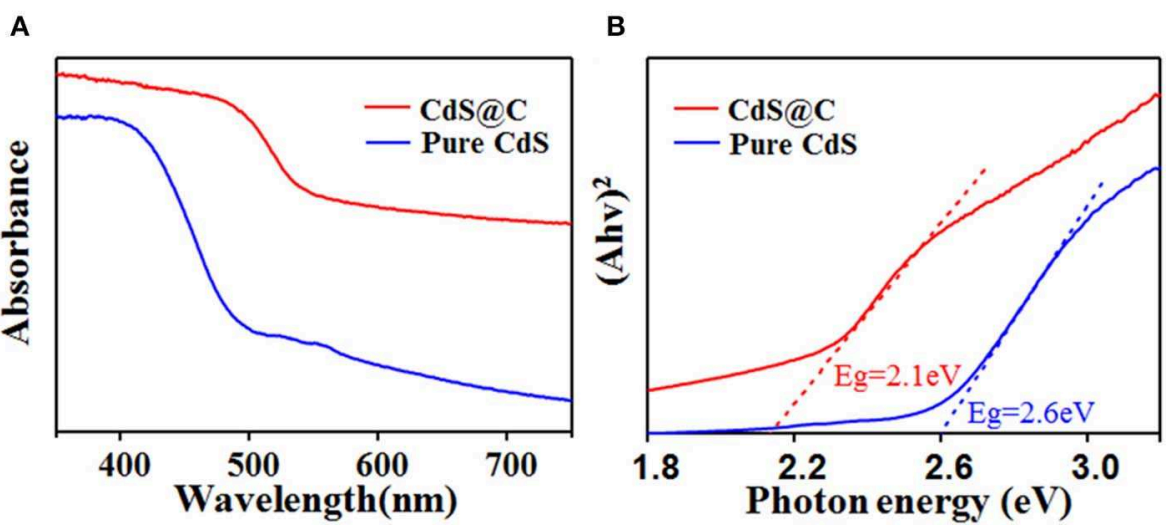

FIGURE 4 | DRS spectra (A) and K-M plots (B) of pure CdS and CdS@C.
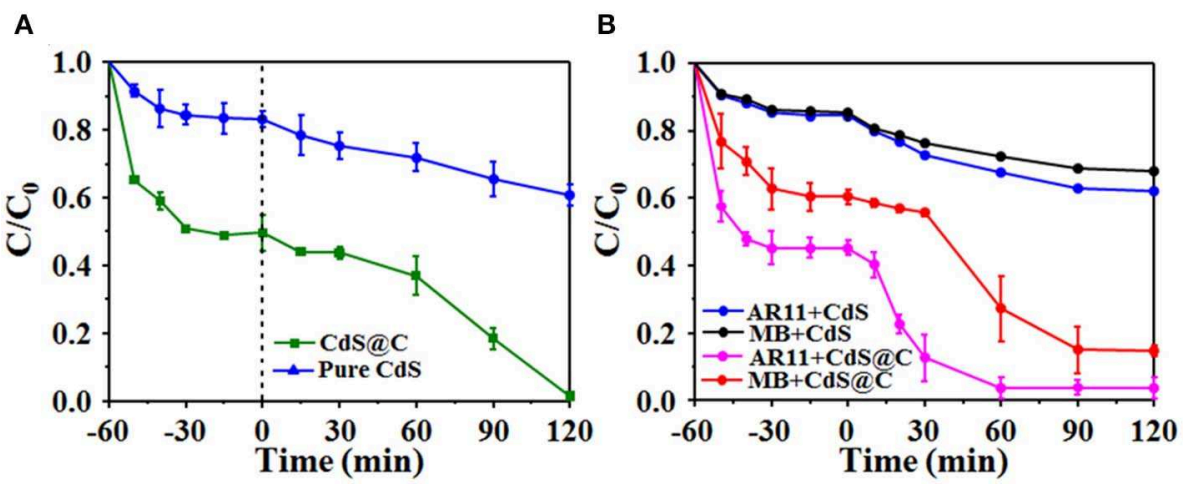

FIGURE 5 | Degradation efficiency of photocatalytic RhB dyes under visible light (A); MB and AR11 degradation efficiency of CdS and CdS@C (B)

CdS@C, ESR and time-dependent fluorescence spectra were obtained by combining the composite with radical scavengers (i.e., DMPO, TA). As shown in Figure 7B, the characteristic peaks of the DMPO-O ${ }_{2}{ }^{-}$- were detected after light irradiation of CdS@C, whereas the ESR signal of DMPO-O ${ }_{2}{ }^{-}$remained silent under dark conditions (Li et al., 2019a, 2020). Moreover, the time-dependent fluorescence spectra of TAOH also confirmed the presence of $\cdot \mathrm{OH}$ during photocatalysis of the CdS@C, 

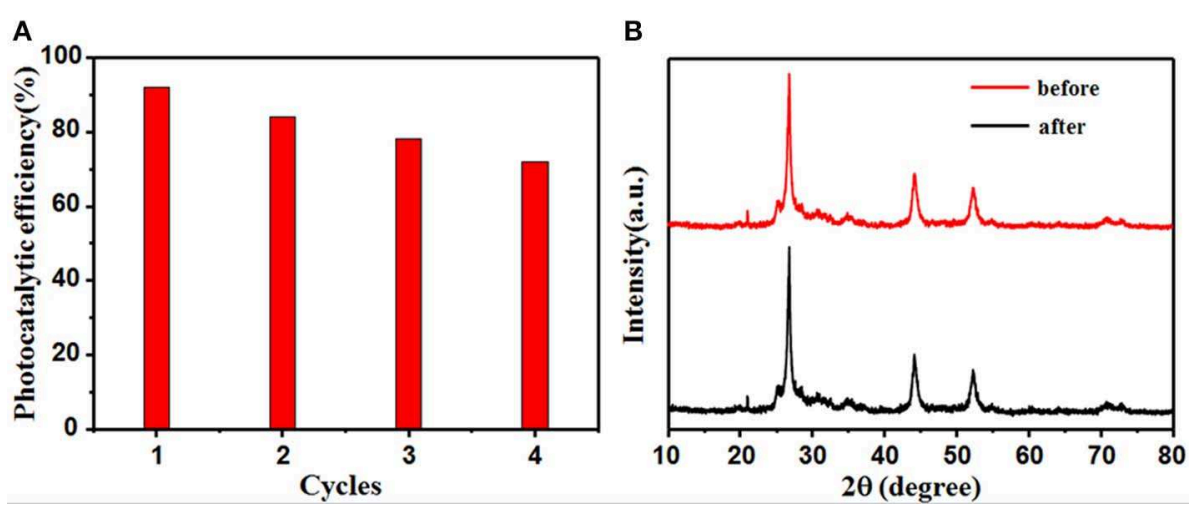

FIGURE 6 | CdS@C stability after 4 reactions of RhB photodegradation (A); XRD pattern of CdS@C before and after the recycling reactions (B).
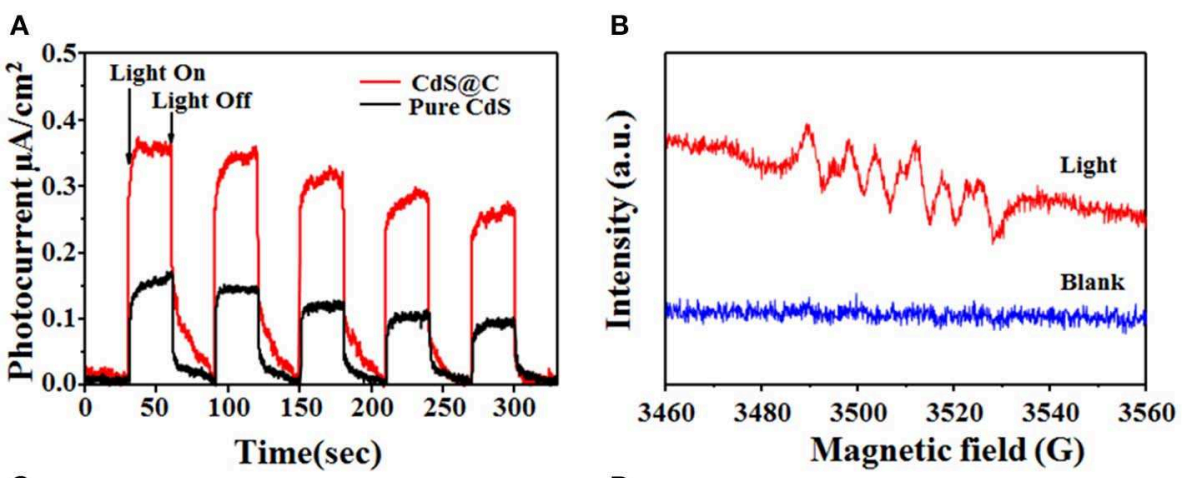

C

D
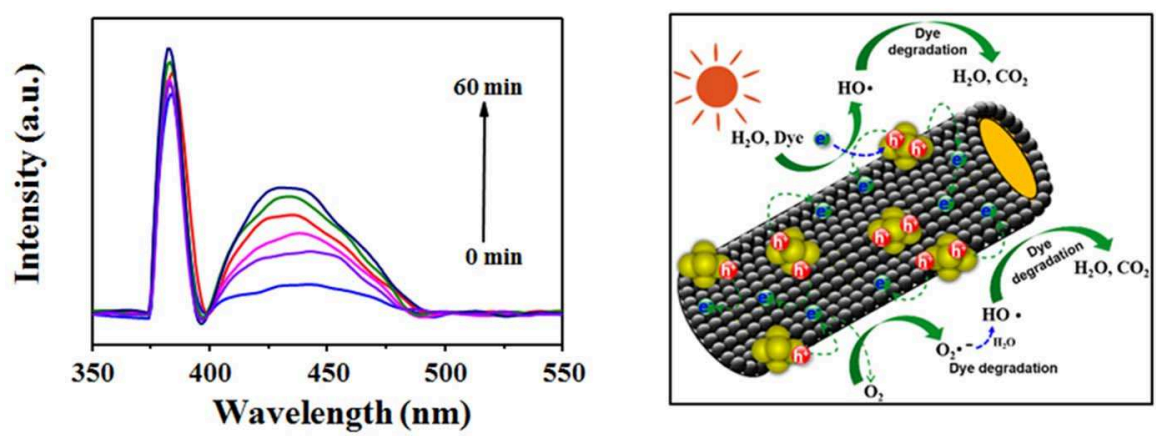

FIGURE 7 | Transient photocurrent spectra of pure CdS and CdS@C under visible light (A); ESR spectra of the superoxide radical captured by DMPO for CdS@C (B); the time-dependent fluorescence intensity of TAOH using CdS@C under visible irradiation (C); photocatalytic degradation mechanism of CdS@C (D).

and the fluorescence intensity increased proportionally with the production of $\cdot \mathrm{OH}$ (Figure 7C) (Li et al., 2019b).

Based on the above research, a possible photodegradation mechanism of the dyes was proposed. As illustrated in Figure 7D, due to the low band gap of CdS@C, visible light was efficiently harvested and used to generate electron-hole pairs. Electron-hole pairs were efficiently separated without recombination due to the good conductivity of the mesoporous biochar support and then participated in the formation of various active species, which participated in the photodegradation of dyes (Zhang et al., 2017; Huang et al., 2018; Li et al., 2019b, 2020).

\section{CONCLUSION}

This work presents the first report of the synthesis of a CdS@C composite photocatalyst by upcycling Cd from plating wastewater. The photocatalytic performance of the composite catalyst obtained was evaluated by using it in the photodegradation of organic dyes.CdS@C contained a mixture of cubic and hexagonal CdS and exhibited a considerably higher light-harvesting capacity and electron-hole separation efficiency. CdS@C displayed enhanced photocatalytic efficiency toward the degradation of organic dyes compared with pure CdS. Further 
investigation of the photocatalytic mechanism suggested that the photodegradation of organic dyes was largely attributable to the continuous formation of catalytically active species $\left(h^{+}, \cdot \mathrm{OH}\right.$, and $\mathrm{O}_{2} \bullet^{-}$) during the photocatalysis of CdS@C.

\section{DATA AVAILABILITY STATEMENT}

The datasets generated for this study are available on request to the corresponding author.

\section{AUTHOR CONTRIBUTIONS}

ZC, S-GZ, and R-ZX designed the research and co-wrote the paper. R-ZX, X-GY, Z-WC, and J-XL conducted experiments and characterized the materials. $\mathrm{RH}$ and $\mathrm{Z}-\mathrm{XC}$ conducted the catalysis.

\section{REFERENCES}

Ahmed, M. J., Okoye, P. U., Hummadi, E. H., and Hameed, B. H. (2019). Highperformance porous biochar from the pyrolysis of natural and renewable seaweed (Gelidiella acerosa) and its application for the adsorption of methylene blue. Bioresour. Technol. 278, 159-164. doi: 10.1016/j.biortech.2019.01.054

Apte, S. K., Garaje, S. N., Valant, M., and Kale, B. B. (2012). Eco-friendly solar light driven hydrogen production from copious waste $\mathrm{H}_{2} \mathrm{~S}$ and organic dye degradation by stable and efficient orthorhombic CdS quantum dots $-\mathrm{GeO}_{2}$ glass photocatalyst. Green Chem. 14, 1455-1462. doi: 10.1039/c2gc16416g

Bantawal, H., Sethi, M., Shenoy, U. S., and Bhat, D. K. (2019). Porous graphene wrapped $\mathrm{SrTiO}_{3}$ nanocomposite: $\mathrm{Sr}-\mathrm{C}$ bond as an effective coadjutant for high performance photocatalytic degradation of methylene blue. ACS Appl. Nano Mater. 2, 6629-6636. doi: 10.1021/acsanm.9b01513

Cao, H. L., Cai, F. Y., Yu, K., Zhang, Y. Q., Lü, J., and Cao, R. (2019). Photocatalytic degaradation of tetracycline antibiotics over CdS/nitrogendoped-carbon composites derived from in situ carbonization of metal-organic frameworks. ACCS Sustain. Chem. Eng. 7, 10847-10854. doi: 10.1021/acssuschemeng.9b01685

Chen, H., Li, W. Y., Wang, J. J., Xu, H. J., Liu, Y. L., Zhang, Z., et al. (2019a). Adsorption of cadmium and lead ions by phosphoric acidmodified biochar generated from chicken feather: selective adsorption and influence of dissolved organic matter. Bioresour. Technol. 292:121948. doi: 10.1016/j.biortech.2019.121948

Chen, L., Li, F., Wei, Y. S., Li, G., Shen, K. X., and He, H. J. (2019b). High cadmium adsorption on nanoscale zero-valent iron coated Eichhornia crassipes biochar. Environ. Chem. Lett. 17, 589-594. doi: 10.1007/s10311-018-0811-y

Chen, T., Zhou, Z. Y., Han, R., Meng, R. H., Wang, H. T., and Lu, W. J. (2015). Adsorption of cadmium by biochar derived from municipal sewage sludge: impact factors and adsorption mechanism. Chemosphere 134, 286-293. doi: 10.1016/j.chemosphere.2015.04.052

Chen, Z., Liu, T., Tang, J. J., Zheng, Z. J., Wang, H. M., Shao, Q., et al. (2018). Characteristics and mechanisms of cadmium adsorption from aqueous solution using lotus seedpod-derived biochar at two pyrolytic temperatures. Environ. Sci. Pollut. Res. Int. 25, 11854-11866. doi: 10.1007/s11356-018-1460-1

Chen, Z., Xing, R. Z., Tang, J. H., Chen, Z. X., Zhang, Z. Y., Liao, H. P., et al. (2019c). Upcycling of Cd hyperaccumulator biomass into a CdS@C nanocomposite with high photocatalytic performance. ACCS Sustain. Chem. Eng. 8, 1388-1395. doi: 10.1021/acssuschemeng.9b05518

Chen, Z. X., Wang, J. T., Xing, R. Z., Wang, Y. H., Wang, S. H., Wei, D., et al. (2019d). Preparation of carbon-supported CdS photocatalysts with high performance of dye photodegradation using cadmiumenriched Perilla frutescens biomass. Inorg. Chem. Commun. 109:107559. doi: 10.1016/j.inoche.2019.107559

\section{FUNDING}

This work was supported by the National Key Research and Development Program of China (Grant No. 2017YFD0800900), the Key Research \& Development Plan of Fujian Province (2017NZ0001-1), the Project of Fujian Provincial Department of Science and Technology, China (2017J05018), the China Postdoctoral Science Foundation (2016M602048), and the National Students' Platform for Innovation and Entrepreneurship Training Program (201810389018). Science Fund for Distinguished Young Scholars of Fujian Agriculture and Forestry University (Grant xjq201904).

\section{SUPPLEMENTARY MATERIAL}

The Supplementary Material for this article can be found online at: https://www.frontiersin.org/articles/10.3389/fchem. 2020.00140/full\#supplementary-material

Clemens, S., Aarts, M. G., Thomine, S., and Verbruggen, N. (2013). Plant science: the key to preventing slow cadmium poisoning. Trends Plant Sci. 18, 92-99. doi: 10.1016/j.tplants.2012.08.003

Cui, X. Q., Shen, Y., Yang, Q. Y., Kawi, S., He, Z. L., Yang, X., et al. (2018). Simultaneous syngas and biochar production during heavy metal separation from Cd/Zn hyperaccumulator (Sedum alfredii) by gasification. Chem. Eng. J. 347, 543-551. doi: 10.1016/j.cej.2018.04.133

Dai, X., Xie, M. L., Meng, S. G., Fu, X. L., and Chen, S. F. (2014) Coupled systems for selective oxidation of aromatic alcohols to aldehydes and reduction of nitrobenzene into aniline using $\mathrm{CdS} / \mathrm{g}-\mathrm{C}_{3} \mathrm{~N}_{4}$ photocatalyst under visible light irradiation. Appl. Catal. B Environ. 158-159, 382-390. doi: 10.1016/j.apcatb.2014.04.035

Gao, B., Yap, P. S., Lim, T. M., and Lim, T. T. (2011). Adsorptionphotocatalytic degradation of Acid Red 88 by supported $\mathrm{TiO}_{2}$ : effect of activated carbon support and aqueous anions. Chem. Eng. J. 171, 1098-1107. doi: 10.1016/j.cej.2011.05.006

Gong, X. M., Huang, D. L., Liu, Y. G., Zeng, G. M., Chen, S., Wang, R. Z., et al. (2019). Biochar facilitated the phytoremediation of cadmium contaminated sediments: Metal behavior, plant toxicity, and microbial activity. Sci. Total Environ. 666, 1126-1133. doi: 10.1016/j.scitotenv.2019.02.215

Guilpain, M., Laubie, B., Zhang, X., Morel, J. L., and Simonnot, M. O. (2018). Speciation of nickel extracted from hyperaccumulator plants by water leaching. Hydrometallurgy 180, 192-200. doi: 10.1016/j.hydromet.2018.07.024

Han, T. Y. J., Worsley, M. A., Baumann, T. F., and Satcher, J. J. H. (2011). Synthesis of $\mathrm{ZnO}$ coated activated carbon aerogel by simple sol-gel route. J. Mater. Chem. 21, 330-333. doi: 10.1039/C0JM03204B

Harsono, S. S., Grundman, P., Lau, L. H., Hansen, A., Salleh, M. A. M., MeyerAurich, A., et al. (2013). Energy balances, greenhouse gas emissions and economics of biochar production from palm oil empty fruit bunches. Resour. Conserv. Recycl. 77, 108-115. doi: 10.1016/j.resconrec.2013.04.005

Harumain, Z. A. S., Parker, H. L., Muñoz, G. A., Austin, M. J., Mcelroy, C. R., Hunt, A. J., et al. (2017). Toward financially viable phytoextraction and production of plant-based palladium catalysts. Environ. Sci. Technol. 51, 2992-3000. doi: 10.1021/acs.est.6b04821

Hayat, M. T., Nauman, M., Nazir, N., Ali, S., and Bangash, N. (2019). Environmental hazards of cadmium: past, present, and future. Cadmium Toxicity and Tolerance in Plants. 7, 163-183. doi: 10.1016/B978-0-12-814864-8.00007-3

He, L. Z., Zhong, H., Liu, G. X., Dai, Z. M., Brookes, P. C., and Xu, J. M. (2019). Remediation of heavy metal contaminated soils by biochar: mechanisms, potential risks and applications in China. Environ. Pollut. 252, 846-855. doi: 10.1016/j.envpol.2019.05.151

Hu, R. Q., Zhang, Z. J., Lin, L. J., Liao, M. A., Tang, Y., Liang, D., et al. (2019). Intercropping with hyperaccumulator plants decreases the cadmium 
accumulation in grape seedlings. Acta Agri. Scand. B Soil Plant Sci. 69, 304-310. doi: 10.1080/09064710.2018.1564786

Huang, H. B., Wang, Y., Cai, F. Y., Jiao, W. B., Zhang, N., Liu, C., et al. (2017). Photodegradation of rhodamine B over biomass-derived activated carbon supported CdS nanomaterials under visible irradiation. Front. Chem. 5:123. doi: $10.3389 /$ fchem. 2017.00123

Huang, H. B., Wang, Y., Jiao, W. B., Cai, F. Y., Shen, M., Zhou, S. G., et al. (2018). Lotus-leaf-derived activated-carbon-supported nano-CdS as energyefficient photocatalysts under visible irradiation. ACSS Sustain. Chem. Eng. 6, 7871-7879. doi: 10.1021/acssuschemeng.8b01021

Huang, H. B., Zhang, N., Yu, K., Zhang, Y. Q., Cao, H. L., Lü, J., et al. (2019). One-step carbothermal synthesis of robust CdS@BPC photocatalysts in the presence of biomass porous carbons. ACSS Sustain. Chem. Eng. 7, 16835-16842. doi: 10.1021/acssuschemeng.9b04395

Hussain, S., Rengel, Z., Qaswar, M., Amir, M., and Zafar-ul-Hye, M. (2019). Arsenic and heavy metal (cadmium, lead, mercury and nickel) contamination in plant-based foods. Plant Hum. Health 2, 447-490. doi: 10.1007/978-3-030-03344-6_20

Inyang, M., Gao, B., Yao, Y., Xue, Y. W., Zimmerman, A. R., Pullammanappallil, P., et al. (2012). Removal of heavy metals from aqueous solution by biochars derived from anaerobically digested biomass. Bioresour. Technol. 110, 50-56. doi: 10.1016/j.biortech.2012.01.072

Keller, C., Ludwig, C., Davoli, F., and Wochele, J. (2005). Thermal treatment of metal-enriched biomass produced from heavy metal phytoextraction. Environ. Sci. Technol. 39, 3359-3367. doi: 10.1021/es0484101

Król, A., Mizerna, K., and Bozym, M. (2020). An assessment of pH-dependent release and mobility of heavy metals from metallurgical slag. J. Hazard Mater. 384:121502. doi: 10.1016/j.jhazmat.2019.121502

Lei, Y. G., Yang, C., Hou, J. H., Wang, F., Min, S. X., Ma, X. H., et al. (2017). Strongly coupled CdS/graphene quantum dots nanohybrids for highly efficient photocatalytic hydrogen evolution: Unraveling the essential roles of graphene quantum dots. Appl. Catal B Environ. 216, 59-69. doi: 10.1016/j.apcatb.2017.05.063

Li, K., Han, M., Chen, R., Li, S. L., Xie, S. L., Mao, C. Y., et al. (2016). Hexagonal@cubic CdS core@shell nanorod photocatalyst for highly active production of $\mathrm{H}_{2}$ with unprecedented stability. Adv. Mater. 28, 8906-8911. doi: 10.1002/adma.201601047

Li, S. J., Chen, J. L., Hu, S. W., Jiang, W., Liu, Y. P., and Liu, J. S. (2020). A novel 3D Z-scheme heterojunction photocatalyst: Ag6Si2O7 anchored on flower-like Bi2WO6 and its excellent photocatalytic performance for the degradation of toxic pharmaceutical antibiotics. Inorg. Chem. Front. 7, 529-541. doi: 10.1039/C9QI01201J

Li, S. J., Chen, J. L., Jiang, W., Liu, Y. P., Ge, Y. M., and Liu, J. S. (2019a). Facile construction of flower-like bismuth oxybromide/bismuth oxide formate $\mathrm{p}-\mathrm{n}$ heterojunctions with significantly enhanced photocatalytic performance under visible light. J. Colloid Interface Sci. 548, 12-19. doi: 10.1016/j.jcis.2019.04.024

Li, S. J., Chen, J. L., Liu, Y. P., Xu, K. B., and Liu, J. S. (2019b). In situ anion exchange strategy to construct flower-like $\mathrm{BiOCl} / \mathrm{BiOCOOH} \mathrm{p}$-n heterostructures for efficient photocatalytic removal of aqueous toxic pollutants. J. Alloys Compd. 781, 582-588. doi: 10.1016/j.jallcom.2018.12.114

Li, S. J., Hu, S. W., Jiang, W., Zhou, Y. T., Liu, J. S., and Wang, Z. H. (2018). Facile synthesis of cerium oxide nanoparticles decorated flower-like bismuth molybdate for enhanced photocatalytic activity toward organic pollutant degradation. J. Colloid Interface Sci. 530, 171-178. doi: 10.1016/j.jcis.2018.06.084

Lv, X. J., Xu, Y. M., Lv, K. L., and Zhang, G. C. (2005). Photo-assisted degradation of anionic and cationic dyes over iron (III)-loaded resin in the presence of hydrogen peroxide. J. Photochem. Photobiol. A Chem. 173, 121-127. doi: 10.1016/j.jphotochem.2005.01.011

Ma, Y. L., Zhao, Z. K., Shen, Z. R., Cai, Q., Ji, H. M., and Meng, L. C. (2017). Hydrothermal carbonation carbon-coated CdS nanocomposite with enhanced photocatalytic activity and stability. Catalysts 7:194. doi: 10.3390/catal7070194

Mahmoodi, N. M., Khorramfar, S., and Najafi, F. (2011). Amine-functionalized silica nanoparticle: preparation, characterization and anionic dye removal ability. Desalination 279, 61-68. doi: 10.1016/j.desal.2011.05.059

Mittal, H., and Khanuja, M. (2019). Optimization of $\mathrm{MoSe}_{2}$ nanostructure by surface modification using conducting polymer for degradation of cationic and anionic dye: photocatalysis mechanism, reaction kinetics and intermediate product study. Dyes Pigments 175:108109. doi: 10.1016/j.dyepig.2019.108109

Nain, P., and Kumar, A. (2019). Initial metal contents and leaching rate constants of metals leached from end-of-life solar photovoltaic waste: an integrative literature review and analysis. Renew. Sust. Energ. Rev. 119:109592. doi: 10.1016/j.rser.2019.109592

Okpalugo, T. I. T., Papakonstantinou, P., Murphy, H., McLaughlin, J., and Brown, N. M. D. (2005). High resolution XPS characterization of chemical functionalised MWCNTs and SWCNTs. Carbon 43, 153-161. doi: 10.1016/j.carbon.2004.08.033

Parker, H. L., Rylott, E. L., Hunt, A. J., Dodson, J. R., Taylor, A. F., Bruce, N. C., et al. (2014). Supported palladium nanoparticles synthesized by living plants as a catalyst for Suzuki-Miyaura reactions. PLoS ONE 9:e871921. doi: 10.1371/journal.pone.0087192

Sadegh, S. M., Bafghi, M. S., Moradkhani, D., and Ojaghi, I. M. (2007). A review on hydrometallurgical extraction and recovery of cadmium from various resources. Miner. Eng. 20, 211-220. doi: 10.1016/j.mineng.2006.07.001

Wang, L., Wang, Y. J., Ma, F., Tankpa, V., Bai, S. S., Guo, X. M., et al. (2019). Mechanisms and reutilization of modified biochar used for removal of heavy metals from wastewater: a review. Sci. Total Environ. 668, 1298-1309. doi: 10.1016/j.scitotenv.2019.03.011

Wu, J., Ren, D. J., Zhang, X. Q., Chen, Z. H., Zhang, S. Q., Li, S., et al. (2019). The adsorption properties of biochar derived from woody plants or bamboo for cadmium in aqueous solution. Desalin. Water Treat. 160, 268-275. doi: 10.5004/dwt.2019.24174

$\mathrm{Xu}, \mathrm{X}$. Y., Cao, X. D., and Zhao, L. (2013). Comparison of rice husk- and dairy manure-derived biochars for simultaneously removing heavy metals from aqueous solutions: role of mineral components in biochars. Chemosphere 92, 955-961. doi: 10.1016/j.chemosphere.2013.03.009

Ye, A., Fan, W. Q., Zhang, Q. H., Deng, W. P., and Wang, Y. (2012). CdSgraphene and CdS-CNT nanocomposites as visible-light photocatalysts for hydrogen evolution and organic dye degradation. Catal. Sci. Technol. 2, 969-978. doi: 10.1039/c2cy20027a

Ye, W. Y., Tang, J. H., Wang, Y. J., Cai, X. X., Liu, H. W., Lin, J. Y., et al. (2019). Hierarchically structured carbon materials derived from lotus leaves as efficient electrocatalyst for microbial energy harvesting. Sci. Total. Environ. 666, 865-874. doi: 10.1016/j.scitotenv.2019.02.300

Zhang, J. J., Li, W. S., Li, Y., Zhong, L., and Xu, C. J. (2017). Self-optimizing bifunctional $\mathrm{CdS} / \mathrm{Cu}_{2} \mathrm{~S}$ with coexistence of light-reduced $\mathrm{Cu} 0$ for highly efficient photocatalytic $\mathrm{H}_{2}$ generation under visible-light irradiation. Appl. Catal. B Environ. 217, 30-36. doi: 10.1016/j.apcatb.2017.05.074

Zhang, X., Houzelot, V., Bani, A., Morel, J. L., Echevarria, G., and Simonnot, M. O. (2014). Selection and combustion of Ni-hyperaccumulators for the phytomining process. Int. J. Phytoremediat. 16, 1058-1072. doi: 10.1080/15226514.2013.810585

Zhang, Y. P., Chen, Z. Y., Xu, W. W., Liao, Q. L., Zhang, H. Y., Hao, S. F., et al. (2020). Pyrolysis of various phytoremediation residues for biochars: chemical forms and environmental risk of Cd in biochar. Bioresour. Technol. 229:122581. doi: 10.1016/j.biortech.2019.122581

Zhao, F. J., Ma, Y. B., Zhu, Y. G., Tang, Z., and Mcgrath, S. P. (2015). Soil contamination in China: current status and mitigation strategies. Environ. Sci. Technol. 49, 750-759. doi: 10.1021/es5047099

Zhu, C., Liu, C. G., Zhou, Y. J., Fu, Y. J., Guo, S. J., Li, H., et al. (2017). Carbon dots enhance the stability of CdS for visible-light-driven overall water splitting. Appl. Catal. B Environ. 216, 114-121. doi: 10.1016/j.apcatb.2017.05.049

Conflict of Interest: The authors declare that the research was conducted in the absence of any commercial or financial relationships that could be construed as a potential conflict of interest.

Copyright (c) 2020 Xing, Li, Yang, Chen, Huang, Chen, Zhou and Chen. This is an open-access article distributed under the terms of the Creative Commons Attribution License (CC BY). The use, distribution or reproduction in other forums is permitted, provided the original author(s) and the copyright owner(s) are credited and that the original publication in this journal is cited, in accordance with accepted academic practice. No use, distribution or reproduction is permitted which does not comply with these terms. 